\title{
Two Gold Surfaces and a Cluster with Remarkable Reactivity for CO Oxidation, a Density Functional Theory Study
}

\author{
A. Hussain - A. J. Muller • B. E. Nieuwenhuys • \\ J. M. Gracia $\cdot$ J. W. Niemantsverdriet
}

Published online: 8 February 2011

(C) The Author(s) 2011. This article is published with open access at Springerlink.com

\begin{abstract}
We calculate the energetics of $\mathrm{CO}$ oxidation on extended surfaces of particular structures chosen to maximize their reactivity towards either $\mathrm{O}_{2}$ dissociation, after which $\mathrm{CO}+\mathrm{O}$ to $\mathrm{CO}_{2}$ is a facile reaction, or to $\mathrm{CO}_{2}$ from molecular $\mathrm{O}_{2}$ and $\mathrm{CO}$. We identified two configurations of $\mathrm{Au}$ atoms for which the energetics of these reactions are feasible. A site consisting of four Au atoms in a square geometry appears well suited for dissociating oxygen.
\end{abstract}

A. J. Muller is on leave from the University of Johannesburg, South Africa.

A. Hussain · J. M. Gracia

Eindhoven University of Technology, STW 3.44, Helix

Building, 5600 MB Eindhoven, The Netherlands

e-mail: a.hussain@tue.nl

J. M. Gracia

e-mail: j.m.graciabudria@tue.nl

\section{A. J. Muller}

Department of Chemistry, University of Johannesburg (APK Campus), P.O. Box 524, Auckland Park, Johannesburg 2006, South Africa

e-mail: mullera@uj.ac.za

B. E. Nieuwenhuys

Eindhoven University of Technology, STW 3.50, Helix

Building, 5600 MB Eindhoven, The Netherlands

e-mail: nieuwe_b@chem.leidenuniv.nl

J. W. Niemantsverdriet $(\bowtie)$

Eindhoven University of Technology, STW 3.47, Helix

Building, 5600 MB Eindhoven, The Netherlands

e-mail: J.W.Niemantsverdriet@tue.nl

A. Hussain - A. J. Muller - B. E. Nieuwenhuys .

J. M. Gracia - J. W. Niemantsverdriet

Schuit Institute of Catalysis, Eindhoven University

of Technology, 5600 MB Eindhoven, The Netherlands
A $\mathrm{Au}_{38}$ cluster exposing this site provides the most favourable energetics for the $\mathrm{CO}$ oxidation.

Keywords $\mathrm{O}_{2}$ adsorption $\cdot \mathrm{O}_{2}$ dissociation $\cdot \mathrm{CO}$ oxidation $\cdot$ Au clusters $\cdot$ DFT $\cdot$ Gold

\section{Introduction}

Catalysts based on gold particles with a size of a few nanometers supported on metal oxides have gained enormous attention in the area of Surf. Sci. and catalysis since Haruta et al. reported their remarkably high activity for low temperature CO oxidation [1]. Since this breakthrough, the reaction has been studied extensively, on supported particles [2-5], atomically dispersed species [6, 7], and Surf. Sci. model systems [8].

Although it is generally accepted that the catalytic activity of Au depends to a large extent on the size of the nanoparticles [9], the question which property of the nanoparticles is responsible for the reactivity has not yet been answered conclusively and the issue of gold's high activity is still under debate [10]. Several explanations have been proposed, including the role of the support [11], quantum size effects, charge transfer to and from the support, support induced-strain, oxygen spill over to and from the support, the Au oxidation state [12], and the role of very low coordinated $\mathrm{Au}$ atoms on $\mathrm{Au}$ nanoparticles [13-15]. Of course, it is possible that several of the aforementioned effects occur simultaneously.

With respect to the mechanism of the $\mathrm{CO}$ oxidation, both atomic and molecular oxygen have been suggested as active species $[5,16,17]$. The energetically difficult step in a mechanism based on O-atoms is the dissociation of $\mathrm{O}_{2}$ on the gold, as the activation energy for this step usually 
exceeds the small heat of adsorption of the $\mathrm{O}_{2}$. In fact, using DFT calculations on stepped Au surfaces, Liu et al. [18] and Fajin et al. [19] have suggested that both atomic and molecular adsorbed oxygen can oxidize $\mathrm{CO}$, the former having the lower activation barrier. Under experimental conditions, water and water derived species such as hydroxyls may play a role [20-22], and reducible support oxides may provide active oxygen for the reaction [23]. It seems plausible that multiple reaction channels and, therefore, multiple $\mathrm{O}_{2}$ activation mechanisms may exist. $\mathrm{O}_{2}$ molecules may directly dissociate on the support, leaving oxygen atoms to diffuse to the gold particles, or they may diffuse molecularly to the gold and react or dissociate at the particle-support interface, or somewhere on the gold particles. Essential intermediates may be atomic, or molecular oxygen, or some type of oxygen-containing species such as peroxides or carbonates [24, 25].

In this paper we ask the question what type of ensemble of gold atoms would be needed to either dissociate $\mathrm{O}_{2}$ into $\mathrm{O}$-atoms, or enable a direct reaction between $\mathrm{O}_{2}$ and $\mathrm{CO}$. To this end we have investigated the relevant reaction steps on various $\mathrm{Au}$ surfaces including low index, stepped and diatomic $\mathrm{Au}$ rows created on $\mathrm{Au}(100)$ employing periodic self-consistent DFT calculations. As some papers report that unsupported clusters may interact strongly with $\mathrm{O}_{2}$ and even catalyze $\mathrm{CO}$ oxidation [26-29], we also include calculations on a gold cluster. We confirm that $\mathrm{O}_{2}$ does not dissociate on a flat surface or even the stepped, relatively reactive (310) surface of gold that we used in previous work [30-32]. However, we find that extended gold surfaces consisting of diatomic rows of Au-atoms on a $\mathrm{Au}(100)$ surface are able to dissociate $\mathrm{O}_{2}$ and allow $\mathrm{CO}$ oxidation, while a $\mathrm{Au}_{38}$ cluster terminated by a similar double dimer facet as the diatomic row structure shows even more favorable energetics for the $\mathrm{CO}$ oxidation from $\mathrm{CO}$ and $\mathrm{O}_{2}$.

\section{Computational Details}

We used the Vienna ab initio simulation package (VASP) [33], which performs an iterative solution of the KohnSham equations in a plane-wave basis set. Plane-waves with a kinetic energy below or equal to $400 \mathrm{eV}$ were included in the calculations. The exchange-correlation energy was calculated within the generalized gradient approximation (GGA) proposed by Perdew and Wang (PW91) [34]. The electron-ion interactions for $\mathrm{C}, \mathrm{O}$ and $\mathrm{Au}$ atoms were described by the projector-augmented wave (PAW) method developed by Blöchl [35]. This is essentially a scheme combining the accuracy of all-electron methods and the computational simplicity of the pseudopotential approach [36].
The relative positions of the Au metal atoms were initially fixed as those in the bulk, with an optimized lattice parameter of $4.18 \AA$ (the experimental value is $4.08 \AA$ ) [37]. The optimized lattice parameter was calculated using the face-centred cubic (fcc) structure unit cell and its reciprocal space was sampled with a $(15 \times 15 \times 15)$ k-point grid generated automatically using the MonkhorstPack method [38]. A first-order Methfessel-Paxton smearing-function with a width $\leq 0.1 \mathrm{eV}$ was used to account for fractional occupancies [39]. Partial geometry optimizations were performed including the RMM-DIIS algorithm [40]. Geometry optimizations were stopped when all the forces were smaller than $0.05 \mathrm{eV} / \AA$. Vibrational frequencies for transition states (TS) were calculated within the harmonic approximation. The adsorbate-surface coupling was neglected and only the Hessian matrix of the adsorbate was calculated [41]. The climbing-image nudged elastic band (cNEB) method [42] was used in this study to determine minimum-energy paths.

Molecules in gas phase were simulated in a $10 \times 12 \times 14 \AA^{3}$ orthorhombic unit cell at the $\Gamma$-point. Non-spin polarized calculations were done for closed shell $\mathrm{CO}$ and $\mathrm{CO}_{2}$ molecules and spin-polarized calculations were performed for open shell species, $\mathrm{O}$ and $\mathrm{O}_{2}$.

\subsection{Spin Polarized Calculations were Done for Adsorbates on Gold}

A four layer slab model, with the two top most layers relaxed, was chosen for constructing diatomic rows on the $\mathrm{Au}(100)$ surface by removing one row of $\mathrm{Au}$ atoms along the vector $b$ as shown in Fig. 1 . A p $(3 \times 2)$ unit cell was used, and its reciprocal space was sampled with $(3 \times 5 \times 1)$ k-point meshes with a vacuum gap $>10 \AA$. The $\mathrm{Au}(100)$ surface was represented with a slab model using five-metal layers of which the top two were relaxed) and for $\mathrm{Au}(310)$ we used 11 layers with the top four relaxed, both with a vacuum gap of $>10 \AA$ to separate the periodic slabs. For the $(100)$ slab, we used a $\mathrm{p}(2 \times 2)$ unit cell with the reciprocal space sampled with $(5 \times 5 \times 1)$ k-point meshes, and for the $\operatorname{Au}(310)$ surface $(3 \times 9 \times 1)$ $\mathrm{k}$-point meshes were used for sampling the reciprocal space of the $(310) \mathrm{p}(2 \times 1)$ unit cell.

$\mathrm{The} \mathrm{Au}_{38}$ nano particle is a three-dimensional metal crystallite cut from metal bulk with low index surfaces (using 111 and 100 planes as basis) to have a cubo octahedral shape. The structure of the particle has been optimized in a fully relaxed state inside a $19 \times 20 \times 21 \AA^{3}$ orthorhombic unit cell, and its reciprocal space was sampled with $(1 \times 1 \times 1)$ k-point mesh generated automatically using the Monkhorst-Pack method. The choice of unit cell allows for vacuum gaps of $>10 \AA$ between particles. 

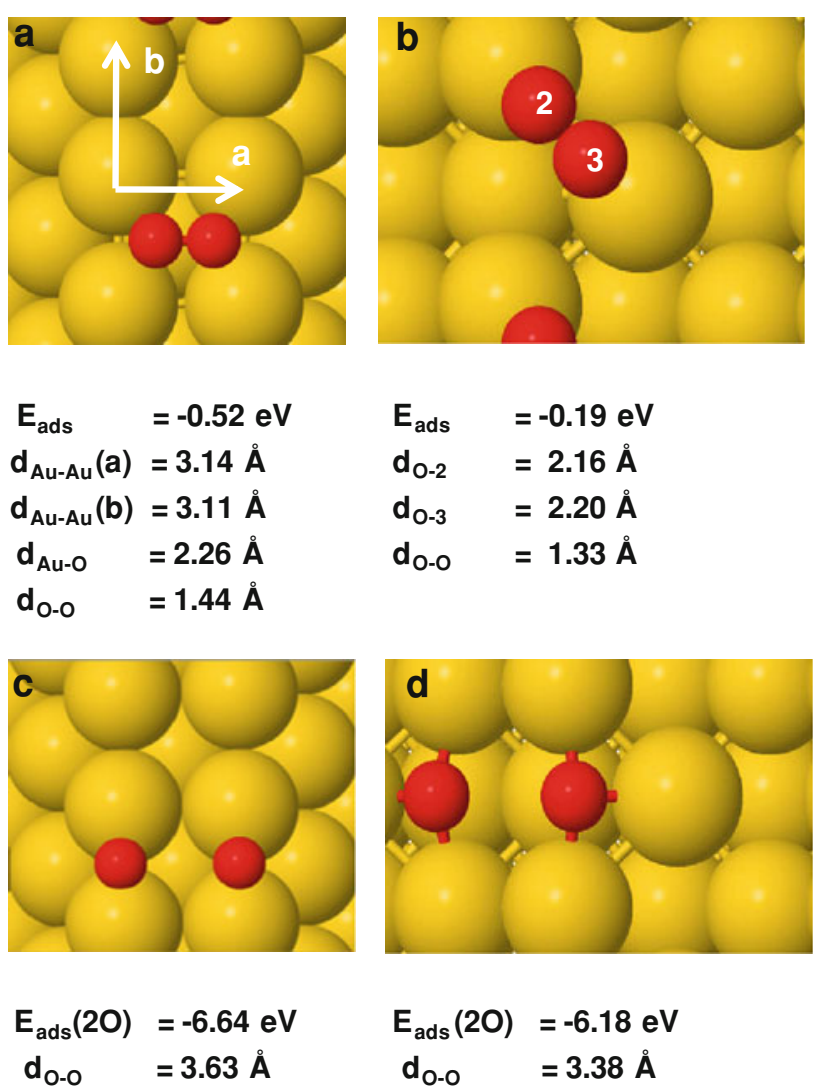

$$
\begin{aligned}
E_{\text {ads }}(20) & =-6.18 \mathrm{eV} \\
\mathrm{d}_{\mathrm{O}-\mathrm{O}} & =3.38 \AA
\end{aligned}
$$

Fig. 1 Top view of the two relatively reactive Au surfaces used in this paper with $\mathrm{O}_{2}$ and $\mathrm{O}$ adsorbed, $\mathbf{a} \mathrm{O}_{2}$ adsorbed on diatomic rows on $\mathrm{Au}(100), \mathbf{b ~ O}_{2}$ on $\mathrm{Au}(310)$, c O-atoms on diatomic rows, d $\mathrm{O}$-atoms on $\mathrm{Au}(310)$. Adsorption energies and characteristic distances are indicated

\section{Results}

The ability of molecular oxygen to dissociate, be it in adsorbed $\mathrm{O}_{2}$ or in a complex with $\mathrm{CO}$, is crucial for $\mathrm{CO}_{2}$ formation. We will first discuss $\mathrm{O}_{2}$ adsorption and dissociation and then the reaction with $\mathrm{CO}$, all on extended surfaces. Finally we discuss the reaction on the $\mathrm{Au}_{38}$ cluster.

\subsection{CO Oxidation on $\mathrm{Au}$ via $\mathrm{O}_{2}$ Dissociation}

\subsubsection{Adsorption of Molecular Oxygen}

Figure 1 shows the two surfaces considered in this paper, namely the $\mathrm{Au}(100)$ with a diatomic row of $\mathrm{Au}$-atoms (Fig. 1a, c) and the stepped $\mathrm{Au}(310)$ (Fig. 1b, d) with molecularly and dissociatively adsorbed oxygen. The interaction of molecular oxygen with gold surfaces varies markedly depending upon the surface structure, location and mode, and for many geometries the interaction is repulsive. This result is an artefact from the calculations, mainly because DFT fails to describe the attractive long-range van der Waals interactions with respect to the short-ranged Pauli repulsion [43]. The hollow-bridge configuration of $\mathrm{O}_{2}$ on the diatomic row in Fig. 1a represents the most stable adsorption mode of $\mathrm{O}_{2}$ on these surfaces $(-0.52 \mathrm{eV})$; single bridges as well as adsorption in double or single bridged modes are a few tenths of an $\mathrm{eV}$ less stable. The distances show that the Au atoms of the row relax in the direction perpendicular to the row, with $\mathrm{Au}-\mathrm{Au}$ distances significantly larger than the $2.96 \AA$ of bulk gold. The $\mathrm{O}-\mathrm{O}$ bond is clearly activated in the hollow adsorption geometry, as evidenced by the elongated $\mathrm{O}-\mathrm{O}$ distance of $1.44 \AA$, which is almost $0.2 \AA$ larger than the bond in gas phase molecular $\mathrm{O}_{2}$ (calculated at $1.24 \AA$; the experimental value is $1.207 \AA$ [44]). Additionally, interaction of $\mathrm{O}_{2}$ for this configuration results in a significant decrease of the stretching frequency $\left(v_{\mathrm{O}-\mathrm{O}}=748 \mathrm{~cm}^{-1}\right)$ with respect to the gas phase reference $\left(1520 \mathrm{~cm}^{-1}\right.$ calculated vs. $1556 \mathrm{~cm}^{-1}$ experimental [44]) indicating substantial bond weakening.

For $\mathrm{O}_{2}$ on the $\mathrm{Au}(310)$ the single bridge mode in Fig. 1b is the most stable one $(-0.19 \mathrm{eV})$, although adsorption on the long bridge at the step comes close. Both should be considered weak chemisorption modes.

Adsorption of $\mathrm{O}_{2}$ on $\mathrm{Au}(100)$ and on $\mathrm{Au} / \mathrm{Au}(100)$, which has an additional $\mathrm{Au}$ atom placed in every fourth hollow site, is even weaker and is on the order of $-0.1 \mathrm{eV}$. Modes of adsorption with the $\mathrm{O}-\mathrm{O}$ molecular axis normal to the surface are predicted to adsorb endothermically.

In summary, $\mathrm{O}_{2}$ interaction with gold, if it exists at all, is weak except for the diatomic row configuration presented in Fig. 1a, where $\mathrm{O}_{2}$ is chemisorbed with an adsorption energy of about $0.52 \mathrm{eV}$ (about $50 \mathrm{~kJ} / \mathrm{mol}$ ).

We conducted Bader charge analysis to quantify the amount of charge transfer from gold to $\mathrm{O}_{2}$ [45]. Au atoms having direct bonding with $\mathrm{O}_{2}$ on the diatomic rows are substantially more oxidized than those on the stepped (310) surface. For instance, for the most stable configuration of Fig. 1a, O-atoms are reduced by $0.53 \mathrm{e}$ and $0.32 \mathrm{e}$ and the $\mathrm{Au}$ atoms are oxidized by $0.23 \mathrm{e}$. However, for the most favorable configuration on (310), O-atoms gained a charge of $0.20 \mathrm{e}$ only, with a loss of charge on the relevant $\mathrm{Au}$ atoms only up to $0.13 \mathrm{e}$. Hence we conclude that the strength of the $\mathrm{O}_{2}$ binding to Au strongly depends upon that structure of Au which is capable of donating charge to the anti-bonding $2 \pi^{*}$ orbitals of $\mathrm{O}_{2}$. The charge transfer weakens the $\mathrm{O}-\mathrm{O}$ bond and consequently the bond elongates.

$\mathrm{Xu}$ and Mavrikakis [25] have studied adsorption and dissociation of $\mathrm{O}_{2}$ on the (111) and (211) surfaces of $\mathrm{Au}$ $($ GGA $=$ PW91). They found no adsorption on (111) but observed weak interaction $(-0.15 \mathrm{eV})$ on the stepped surface with $\mathrm{O}_{2}$ in a top-bridge-top configuration at the step. An adsorption energy of $-0.12 \mathrm{eV}$ was reported in an 
earlier paper by Mavrikakis et al. [46] for $\mathrm{O}_{2} \mathrm{Au}(211)$ with the molecular $\mathrm{O}-\mathrm{O}$ axis parallel to the surface. Again, no adsorption was found on $\mathrm{Au}(111)$. Fajin et al. [47] have recently investigated the adsorption of $\mathrm{O}_{2}$ on $\mathrm{Au}(321)$ in detail $(\mathrm{GGA}=\mathrm{PW} 91)$. The highest $E_{\mathrm{ads}}(-0.17 \mathrm{eV})$ occurred with $\mathrm{O}_{2}$ on the bridge site. $A$ value of $<-0.05 \mathrm{eV}$ is reported on $\mathrm{Au}(221)(\mathrm{GGA}=\mathrm{PBE})$ [18]. A recent experimental study also reports a weak interaction of $\mathrm{O}_{2}$ with $\mathrm{Au}(111)$ [48]. Experimental results for the diatomic rows of Fig. 1 are not available.

\subsubsection{Adsorption of Atomic Oxygen}

Atomic oxygen, once available, adsorbs readily on the gold surfaces of Fig. 1. As we are interested in dissociation, we immediately consider the adsorption of two O-atoms on adjacent sites. Figure 1c shows the most stable configuration with two $\mathrm{O}$-atoms on outer bridge positions of the diatomic row structure. The joint adsorption energy amounts to $-6.64 \mathrm{eV}$ per two atoms (for comparison, the strongest adsorption bond for a single $\mathrm{O}$-atom, which resides in the inner bridge along the b-vector amounts to $-3.49 \mathrm{eV}$; the adsorption energy for a single $\mathrm{O}$-atom in the fourfold hollow site is $-3.42 \mathrm{eV}$ ). This configuration is exothermic by $-0.38 \mathrm{eV}$ ) with respect to molecular $\mathrm{O}_{2}$ in the gas phase. The adsorption energy is $-3.32 \mathrm{eV}$ per oxygen atom with respect to gas phase atomic oxygen. Coadsorption of two O-atoms on the fourfold hollow positions is significantly less favorable $(-5.58$ or $-2.79 \mathrm{eV}$ per $\mathrm{O}$ atom).

$\mathrm{On} \mathrm{Au}(310)$ the most stable geometry of two O-atoms is as shown in Fig. 1d. A single O-atom would be adsorbed with energy of $-3.32 \mathrm{eV}$. However, for two adjacent $\mathrm{O}$-atoms, the joint adsorption energy of $-6.18 \mathrm{eV}$ is 0.08 and $0.27 \mathrm{eV}$ endothermic with respect to $\mathrm{O}_{2}$ in the gas phase or adsorbed $\mathrm{O}_{2}$ respectively.
Adsorption energies of -2.47 to $-2.71 \mathrm{eV}$ for $\mathrm{O}$ on the fcc hollow site of $\mathrm{Au}(111)$ have been reported in literature [18, 49, 50]. Energies reported by Liu et al. [18] $(\mathrm{GGA}=\mathrm{PBE})$ on the step bridge site of $\mathrm{Au}(221)$ and $\mathrm{Au}(211)$ are -2.91 and $-3.09 \mathrm{eV}$, respectively. Fajin et. al. [47] $(\mathrm{GGA}=\mathrm{PW} 91)$ reported $-3.30 \mathrm{eV}$ for $\mathrm{O}$ on the most stable sites of $\mathrm{Au}(321)$. All these values are in good agreement with our results.

We conclude that coadsorption of two O-atoms on the diatomic rows as in Fig. 1c is expected to provide the least unfavorable thermodynamic driving force for dissociation, with an endothermicity of about $0.14 \mathrm{eV}$ with respect to adsorbed molecular $\mathrm{O}_{2}$, see Fig. 2 .

The high adsorption energies of $\mathrm{O}$-atoms on and near the steps clearly demonstrate how Au atoms of low coordination are more reactive. Again, the strongest adsorption of $\mathrm{O}$-atoms is on the diatomic rows. For comparison we note however that the highest adsorption energy on this corrugated $\mathrm{Au}$ surface $(-3.5 \mathrm{eV})$ is still $\sim 0.50 \mathrm{eV}$ lower than that on the least reactive surface of platinum, (4.00-4.30 eV for $\mathrm{O} / \mathrm{Pt}(111)$ ), where the $\mathrm{O}_{2}$ is experimentally seen to dissociate [51].

\subsubsection{Dissociation of Molecular Oxygen}

For $\mathrm{O}_{2}$ to dissociate it is imperative that the transition state for dissociation has a lower activation energy than that for desorption of the $\mathrm{O}_{2}$. Among the surfaces and geometries of adsorbed $\mathrm{O}_{2}$ and the two co-adsorbed O-atoms considered in this paper we found only one feasible route for dissociation, namely on the diatomic Au rows on $\mathrm{Au}(100)$. All other combinations led to transition states with activation energies much higher than the $\mathrm{O}_{2}$ heat of adsorption.

Figures 1a and c appear as likely start and end configurations for $\mathrm{O}_{2}$ dissociation. Both are enthalpically stable
Fig. 2 Potential energy diagram for $\mathrm{CO}$ oxidation on the diatomic $\mathrm{Au}$ rows on $\mathrm{Au}(100)$. Top (below) and side (above) views for $\mathrm{O}_{2}$ adsorption and dissociation, $\mathrm{CO}$ and $\mathrm{O}$ coadsorption and $\mathrm{CO}_{2}$ formation are shown. The critical step is $\mathrm{O}_{2}$ dissociation which has an activation barrier almost equal to that of $\mathrm{O}_{2}$ desorption. All further steps towards $\mathrm{CO}_{2}$ however, are thermodynamically very favorable. Note that the process ends with an $\mathrm{O}$-atom on the surface, making the next reaction with adsorbed $\mathrm{CO}$ a facile one $(0.02 \mathrm{eV}$ activation energy and $2.22 \mathrm{eV}$ exothermic)

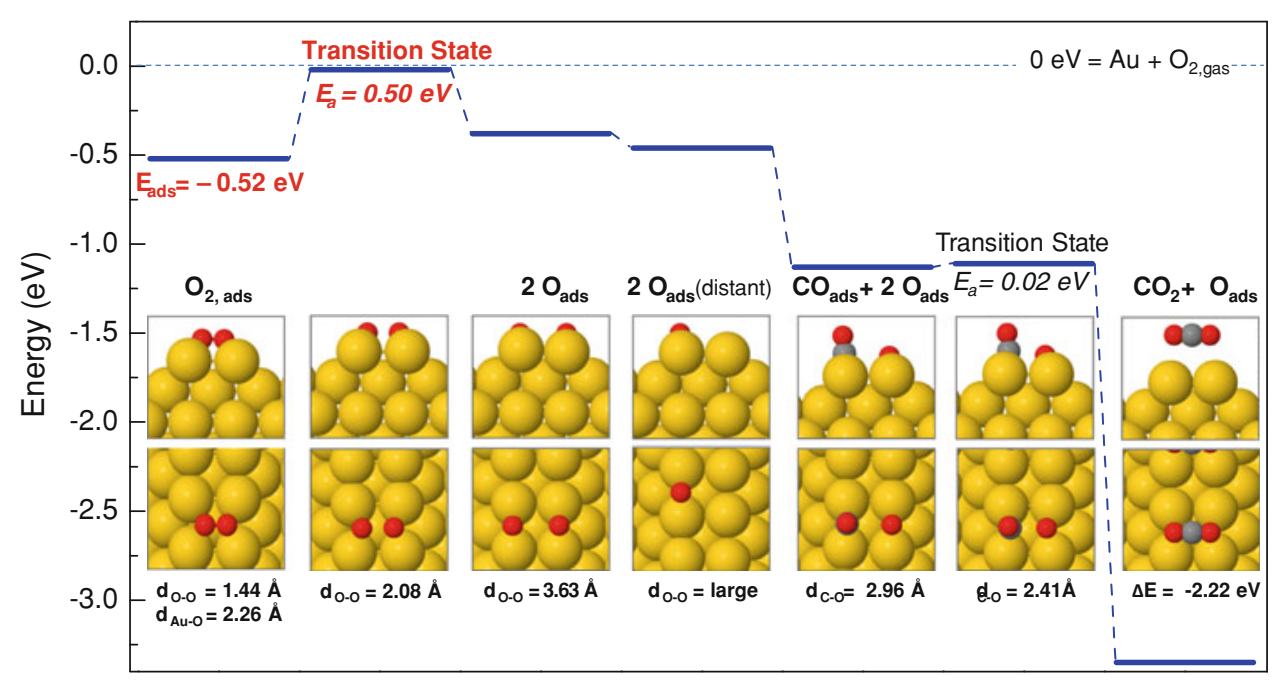

reaction coordinate 
with respect to gas phase oxygen, and the reaction is only slightly endothermic $(0.14 \mathrm{eV})$. We calculate a transition state with an activation barrier of $0.5 \mathrm{eV}$, which is about the same as the activation energy for desorption of $\mathrm{O}_{2}$ (0.52 eV), see Fig. 2.

In the transition state, which is symmetric, the $\mathrm{O}-\mathrm{O}$ bond length increases from 1.44 to $2.08 \AA$ and each $\mathrm{O}$-atom is at a distance of $2.07 \AA$ from the nearest $\mathrm{Au}$ atoms. To ascertain whether the above arrangement is a saddle point or a local minimum, vibrational analysis was carried out. The transition state was characterized by a unique imaginary frequency of $265 i \mathrm{~cm}^{-1}$ and the normal mode analysis shows that the $\mathrm{O}$-atoms move in opposite directions. As the activation energy for dissociation is almost similar to that for desorption, both processes will compete. In general, desorption has a higher pre-exponential factor than surface dissociation, caused by the entropy difference between adsorbed and free molecules. Nevertheless, it is well possible that part of the $\mathrm{O}_{2}$ will dissociate into $\mathrm{O}$-atoms on the surface.

\subsubsection{CO Adsorption}

CO adsorbs weakly on close-packed surfaces of gold, but when the surface contains steps, adsorption energies become appreciable. On $\mathrm{Au}(310) \mathrm{CO}$ bound linearly through the $\mathrm{C}$-atom to the low-coordinated $\mathrm{Au}$ atoms at the step yields the highest adsorption energy, namely $-0.73 \mathrm{eV}$. For details we refer to our previous work [32].

On the diatomic rows $\mathrm{CO}$ binds preferentially on bridge sites, with an adsorption energy of $-0.75 \mathrm{eV}$. The bridge configuration is a local minimum with real frequencies, the $\mathrm{CO}$ stretch being at $1890 \mathrm{~cm}^{-1}$. The values of $E_{\text {ads }}$ are on the order of $0.2 \mathrm{eV}$ higher than on the corresponding sites of $\mathrm{Au}(100)$ [32]. Adsorption on the top site $(-0.63 \mathrm{eV})$ has two imaginary modes at $50 i, 95 i \mathrm{~cm}^{-1}$ and corresponds to a second order saddle point. As the adsorption energies on bridge and top sites are very similar, we conclude that the $\mathrm{CO}$ molecule will be able to diffuse easily on the diatomic rows.

\subsubsection{CO Oxidation on Diatomic Rows}

The diatomic row may catalyze the $\mathrm{CO}$ oxidation reaction as illustrated in Fig. 2. Once CO and O-atoms are coadsorbed on the diatomic row, reaction takes place spontaneously with a negligible activation barrier of $0.02 \mathrm{eV}$. Similarly low activation energies have been observed in other studies [19, 52]. In the most favorable coadsorption state $\mathrm{CO}$ and $\mathrm{O}$ are both on bridge positions (see Fig. 2). In the transition state the carbon atom of $\mathrm{CO}$ and $\mathrm{O}$-atom are $2.41 \AA$ apart. It has one imaginary frequency of $112 i \mathrm{~cm}^{-1}$, and is thus a true transition state. Two other combinations were tried, one with $\mathrm{CO}$ and $\mathrm{O}$ both on bridge locations along the vector $\mathrm{b}$ and the other with positioning $\mathrm{CO}$ on top and $\mathrm{O}$ on adjacent bridge. The former geometry is $0.45 \mathrm{eV}$ less stable indicating substantial repulsion. The latter leads to the formation of $\mathrm{CO}_{2}$ right away. $\mathrm{CO}_{2}$ formation is highly exothermic $(-2.22 \mathrm{eV})$ and thus thermodynamically favorable. As its adsorption energy is very small, it desorbs instantaneously upon formation.

\subsection{CO Oxidation via OCOO Complex Formation and Decomposition}

We have also investigated the direct reaction between $\mathrm{CO}$ and $\mathrm{O}_{2}$. Fig. 3 shows the reaction pathway on the (310) surface. A few initial configurations for carbon monoxide and molecular oxygen coadsorbed on the (310) surface were considered. Knowing that $\mathrm{O}_{2}$ is adsorbed weakly on this gold surface, and that $\mathrm{CO}$ preferentially chemisorbs at the outer step [32], the combination of coadsorbates as well
Fig. 3 Energy profile for $\mathrm{CO}_{2}$ formation on $\mathrm{Au}(310)$ via a direct reaction of $\mathrm{CO}$ with molecular $\mathrm{O}_{2}$. The zero level corresponds to gas phase $\mathrm{CO}$, $\mathrm{O}_{2}$ and the clean slab

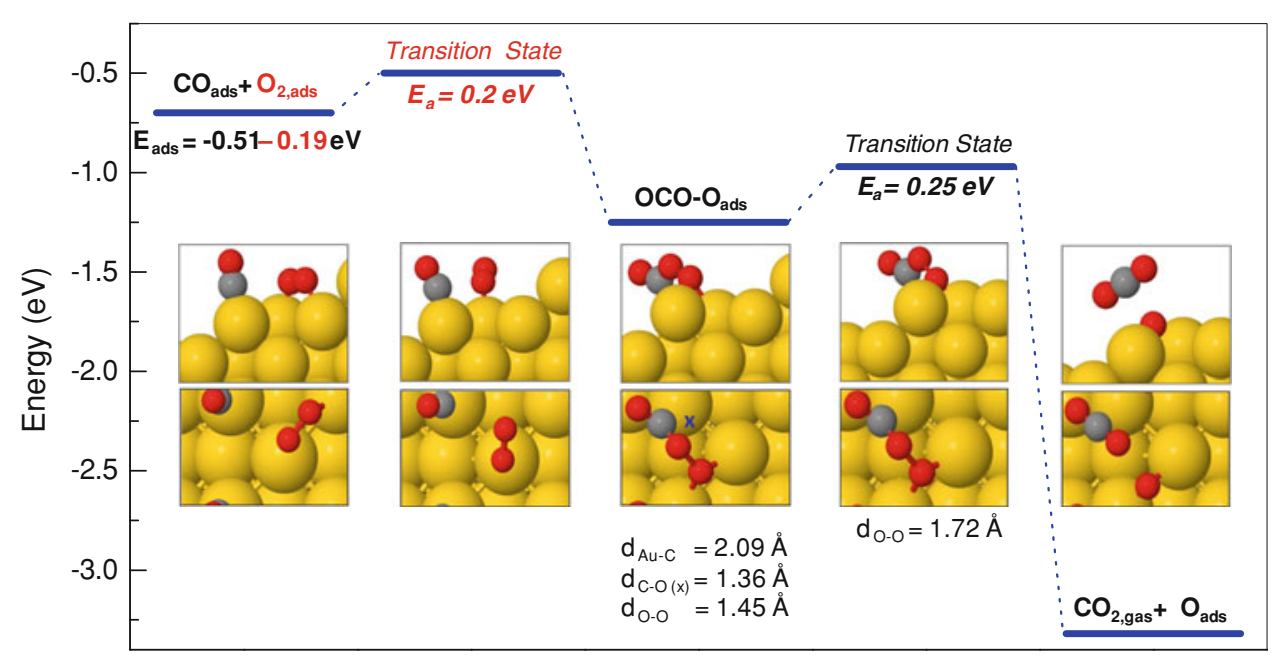

reaction coordinate 
as the transition state shown at the start of the reaction in Fig. 3 come out as the most likely. The adsorption energy for $\mathrm{CO}$ and $\mathrm{O}_{2}$ equals $-0.7 \mathrm{eV}$. It is important to note that the differential adsorption energy of the $\mathrm{O}_{2}$ in this configuration is $-0.19 \mathrm{eV}$, which effectively corresponds to weak chemisorption. In the transition state, the carbon atom of the $\mathrm{CO}$ molecule interacts directly with the $\mathrm{O}-\mathrm{O}$ bond of the $\mathrm{O}_{2}$ molecule, with a transition state characterized by a small activation barrier of $0.20 \mathrm{eV}$ and a unique imaginary frequency of $113 i \mathrm{~cm}^{-1}$.

Hence, the transition state for the direct reaction between $\mathrm{CO}$ and $\mathrm{O}_{2}$ has an activation energy of $0.2 \mathrm{eV}$, i.e. of the same magnitude as the energy with which $\mathrm{O}_{2}$ binds to the $\mathrm{Au}$ (310) surface. Our results are rationalized in terms of enthalpy, and we do not consider entropy. $\mathrm{O}_{2}$ molecules on the surface may react with $\mathrm{CO}$, but the barrier to desorption, which is entropically favoured, is similar. Hence desorption will be more likely than reaction.

This OCOO species on the surface is $0.7 \mathrm{eV}$ more stable than the co-adsorbate configuration. It has been invoked in other studies on $\mathrm{Au}(321)$ and $\mathrm{Au}(211)$ surfaces [19]. The structural parameters of the OCO-O complex are in excellent agreement with these studies. However, on $\mathrm{Au}(321)$ and (211) the activation energies for OCOO formation are substantially higher $(0.58-0.68 \mathrm{eV})$ than the $0.20 \mathrm{eV}$ on $\mathrm{Au}(310)$ in our work. Interestingly, an even lower barrier of $0.08 \mathrm{eV}$ was calculated for OCOO formation on a $\mathrm{Au}$ strip supported on $\mathrm{ZrO}_{2}$ [52].

Once the OCOO intermediate forms, it reacts via a $0.25 \mathrm{eV}$ barrier to $\mathrm{CO}_{2}$ and an adsorbed $\mathrm{O}$-atom. Literature reports barriers of $0.33-0.43 \mathrm{eV}$ for dissociation of the OCOO species $[19,52]$. The remaining $\mathrm{O}$-atom reacts with $\mathrm{CO}$ almost without barrier $(0.04 \mathrm{eV})$. The process is highly exothermic $(-2.85 \mathrm{eV})$.

While the diatomic rows represent the most reactive $\mathrm{Au}$ surface for $\mathrm{O}_{2}$ splitting reported thus far, this structure is almost inactive for OCOO complex formation. Thus the diatomic row structure is active enough for $\mathrm{O}_{2}$ dissociation and oxidation of $\mathrm{CO}$, but not via the direct reaction between $\mathrm{O}_{2}$ and CO. Conversely, on the (310) surface both OCO-O compound formation and subsequent $\mathrm{O}-\mathrm{O}$ bond cleavage are thermodynamically favorable and proceed by surmounting small energy barriers of 0.20 and $0.25 \mathrm{eV}$ for the two steps. Hence this channel may be operative for catalyzing the $\mathrm{CO}$ oxidation on nanoparticles with appropriate steps.

\subsection{CO Oxidation on $\mathrm{Au}_{38}$ Cluster}

The $\mathrm{Au}_{38}$ cluster shown in Fig. 4 exposes (111) facets consisting of seven atoms and (100) facets of four atoms. The latter bear similarity to the diatomic row structure on $\mathrm{Au}(100)$ in Figs. 1 and 2, and is therefore of particular interest for the purpose of this study.

Figure 4 starts with the adsorption and dissociation of $\mathrm{O}_{2}$ on the (100) facet, in geometries that are equivalent to the ones investigated on the extended diatomic row surface. It is seen that $\mathrm{O}_{2}$ adsorbs with an appreciable strength $(-0.78 \mathrm{eV})$ on the cluster, while the activation energy for dissociation is only $0.43 \mathrm{eV}$, the dissociation step itself being exothermic. Hence this cluster successfully binds and
Fig. 4 Energy scheme for $\mathrm{CO}$ oxidation via $\mathrm{O}_{2}$ dissociation on a $\mathrm{Au}_{38}$ cluster

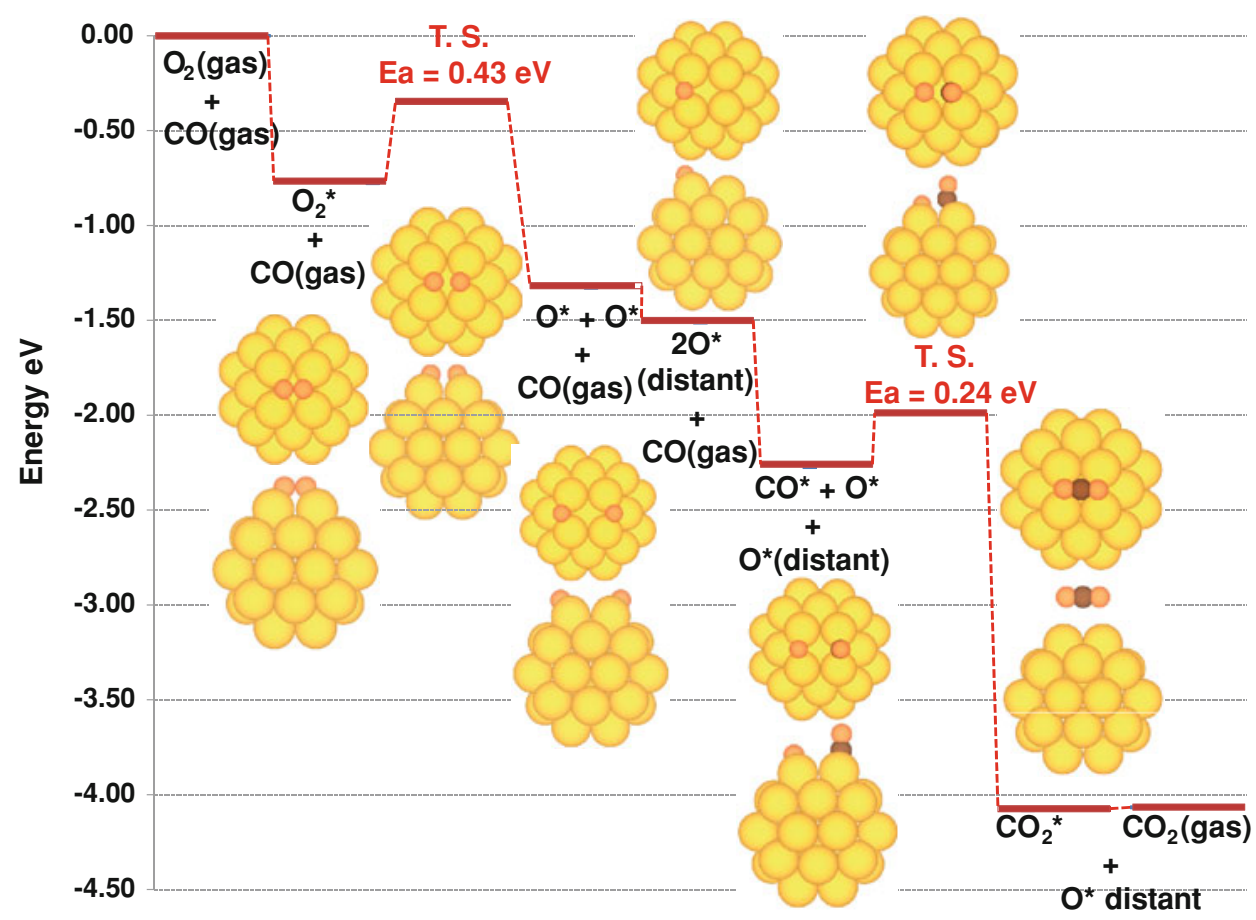


dissociates $\mathrm{O}_{2}$ in a similar fashion as the diatomic row structure in Figs. 1 and 2. The two adjacent O-atoms after dissociation show some repulsion, hence we continue the calculations by taking twice the energy of a single O-atom per cluster. Coadsorption of $\mathrm{CO}$ on the same (100) facet is feasible, with a differential adsorption energy of $-0.76 \mathrm{eV}$. In the transition state the $\mathrm{CO}$ moves towards the O-atom, which involves a small barrier of $0.24 \mathrm{eV}$ after which $\mathrm{CO}_{2}$ forms and desorbs.

We compare our results with those of Róldan et al. [29, 53], who reported $\mathrm{O}_{2}$ adsorption energies in the range of -0.19 to $-0.91 \mathrm{eV}$ on $\operatorname{Au}_{\mathrm{n}}(n=25,38,55$, and 79) clusters. $\mathrm{Au}_{38}$ had the highest $E_{\text {ads }}$ for $\mathrm{O}_{2}$ and was found to dissociate $\mathrm{O}_{2}$ with an activation barrier of $0.46 \mathrm{eV}$ [29] in excellent agreement with our values.

Róldan et al. also investigated the effect of exchangecorrelation functional on the adsorption and dissociation energy of $\mathrm{O}_{2}$ [53]. Values calculated using PW91 were larger than the PBE by roughly $0.20 \mathrm{eV}$, however, the effect of changing the functional on the activation barriers is smaller. Overestimation of about $0.30 \mathrm{eV}$ in binding of $\mathrm{O}_{2}$ to gold clusters employing GGA $=$ PW91 has been reported in previous works as well $[54,55]$.

\section{Discussion}

In this paper we address $\mathrm{CO}$ oxidation on extended surfaces of particular structure, chosen such to maximize their reactivity towards either $\mathrm{O}_{2}$ dissociation, after which $\mathrm{CO}+\mathrm{O}$ is usually a facile reaction step, or to $\mathrm{CO}_{2}$ formation between $\mathrm{CO}$ and molecular oxygen. We identified two configurations of Au atoms for which the energetics of these reactions appear feasible.

Following the steps of normal Langmuir-Hinshelwood mechanisms, the reactants first need to adsorb on the surface. Figure 5 presents an overview of how $\mathrm{CO}$ and $\mathrm{O}_{2}$ adsorb on a number of gold surfaces. Carbon monoxide chemisorbs in principle on all gold surfaces, with the exception of the close-packed $\mathrm{Au}(111)$ surface, where the adsorption energy is characteristic for weak chemisorption. Figure 5 clearly shows the trend that $\mathrm{CO}$ adsorbs more strongly when the coordination of the gold atom decreases. The strongest bond $(-0.88 \mathrm{eV})$ is formed with the fourfold coordination of the additional $\mathrm{Au}$ atom on the $\mathrm{Au}(100)$ surface, but adsorption of $\mathrm{CO}$ on the stepped (310), the diatomic row structure and the $\mathrm{Au}_{38}$ cluster also show considerable bond strengths between -0.73 and $-0.79 \mathrm{eV}$. For $\mathrm{O}_{2}$ the situation is more critical. Irrespective of whether the mechanism of $\mathrm{CO}$ oxidation proceeds via dissociated or molecular $\mathrm{O}_{2}$, the molecule needs to bound sufficiently strong that the activation energy of the subsequent step will not exceed the adsorption energy, otherwise the $\mathrm{O}_{2}$ will probably desorb. Of all the surfaces considered in Fig. 5, only the diatomic row and the $\mathrm{Au}_{38}$ cluster bind the $\mathrm{O}_{2}$ sufficiently strong. Interestingly the surface exposing the single $\mathrm{Au}$ atoms with the lowest coordination of all $(N=4)$ does not interact appreciably with $\mathrm{O}_{2}$. The diatomic row and the $\mathrm{Au}_{38}$ cluster have in common that they expose ensembles of four $\mathrm{Au}$ atoms of relatively low coordination in a square array to which the $\mathrm{O}_{2}$ binds in the "hollow-four centre bridge" configuration of Fig. 1a with
Fig. 5 Overview of adsorptions and reactions relevant for $\mathrm{CO}$ oxidation on different gold surfaces

\begin{tabular}{|c|c|c|c|c|c|c|}
\hline \multicolumn{2}{|c|}{ Au surface } & \multicolumn{4}{|c|}{ Adsorption energies } & \multirow[t]{2}{*}{ CO oxidation } \\
\hline & & $\mathrm{CO}$ & $\mathrm{O}_{2}$ & Ovs $O_{g a s}$ & $\mathrm{O} v s \mathrm{O}_{2, \text { gas }}$ & \\
\hline $\mathrm{Au}(111)$ & $\begin{array}{l}308308 \\
30303\end{array}$ & $\begin{array}{c}-0.25 \mathrm{eV} \\
\text { non specific }\end{array}$ & 0 & $-2.70 \mathrm{eV}$ & $+0.43 \mathrm{eV}$ & No chemisorption of reactants \\
\hline $\mathrm{Au}(100)$ & $\begin{array}{ll}9000 \\
8080 \\
8080\end{array}$ & $\begin{array}{l}-0.55 \mathrm{eV} \\
\text { bridged }\end{array}$ & $-0.12 \mathrm{eV}$ & $-3.14 \mathrm{eV}$ & $-0.01 \mathrm{eV}$ & $\begin{array}{l}\text { Co chemisorbs, } \\
\text { but no } \mathrm{O}_{2} \text { activation }\end{array}$ \\
\hline $\mathrm{Au} / \mathrm{Au}(100)$ & $\begin{array}{l}383 \\
8383 \\
8383\end{array}$ & $\begin{array}{l}-0.88 \mathrm{eV} \\
\text { on top }\end{array}$ & $-0.14 \mathrm{eV}$ & $-2.87 \mathrm{eV}$ & $+0.24 \mathrm{eV}$ & $\begin{array}{l}\text { CO chemisorbs, } \\
\text { but no } \mathrm{O}_{2} \text { activation }\end{array}$ \\
\hline $\mathrm{Au}(310)$ & 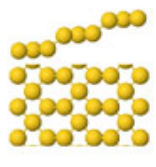 & $\begin{array}{l}-0.73 \mathrm{eV} \\
\text { linear, at step }\end{array}$ & $p^{-0.19 e V}$ & $-3.32 \mathrm{eV}$ & $-0.19 \mathrm{eV}$ & $\begin{array}{l}\mathrm{CO}+\mathrm{O}_{2} \text { is energetically feasible, } \\
\text { but as } \mathrm{O}_{2} \text { is physisorbed, reaction } \\
\text { competes with diffusion and } \\
\text { desorption of } \mathrm{O}_{2}\end{array}$ \\
\hline $\begin{array}{l}\mathrm{Au}_{2} / \mathrm{Au}(100) \\
\text { diatomic rows }\end{array}$ & 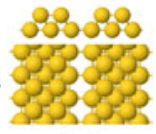 & $\begin{array}{l}-0.75 \mathrm{eV} \\
\text { Bridged }\end{array}$ & $-0.52 \mathrm{eV}$ & $-3.49 \mathrm{eV}$ & $-0.36 \mathrm{eV}$ & $\begin{array}{l}\mathrm{O}_{2} \text { dissociation energetically } \\
\text { feasible, but competes with } \\
\mathrm{O}_{2} \text { desorption; } \mathrm{CO}+\mathrm{O} \text { is easy }\end{array}$ \\
\hline $\mathrm{Au}_{38}$ cluster & & $\begin{array}{l}-0.79 \\
\text { bridged }\end{array}$ & $-0.78 \mathrm{eV}$ & $-3.88 \mathrm{eV}$ & $-0.76 \mathrm{eV}$ & $\begin{array}{l}\text { Straightforward reaction by } \mathrm{O}_{2} \\
\text { dissociation, and } \mathrm{CO}_{2} \text { formation }\end{array}$ \\
\hline
\end{tabular}


the molecular axis parallel to the surface. This site can also accommodate the O-atoms after dissociation. On the diatomic row, the four $\mathrm{Au}$ atoms in the square ensemble each have a coordination number of seven $(N=7) . \mathrm{O}_{2}$ binds appreciably $(-0.52 \mathrm{eV})$ as do the two O-atoms after dissociation, although the dissociation is slightly endothermic $(0.14 \mathrm{eV})$ and the activation energy for dissociation is with $0.5 \mathrm{eV}$ about equal to the $\mathrm{O}_{2}$ heat of adsorption. However, the same configuration on the $\mathrm{Au}_{38}$ cluster offers the lowest coordination of the Au atoms $(N=6$ for each of the four $\mathrm{Au}$ atoms), and here the dissociation of $\mathrm{O}_{2}$ becomes exothermic, with the concomitantly lower activation energy of $0.43 \mathrm{eV}$, which is considerably smaller than the $\mathrm{O}_{2}$ adsorption energy.

Our results are in good agreement with those of Róldan et al. [29,53], who studied the $\mathrm{O}_{2}$ dissociation on a number of $\mathrm{Au}_{\mathrm{n}}$ clusters ( $n=25,38,55$, and 79), among which $\mathrm{Au}_{38}$ shows the highest reactivity towards $\mathrm{O}_{2}$. The second best is $\mathrm{Au}_{25}$ which interestingly also exposes the square $\mathrm{Au}_{4}$ arrangement.

Although $\mathrm{CO}$ oxidation via $\mathrm{O}_{2}$ dissociation on the $\mathrm{Au}_{38}$ cluster appears as a realistic possibility, the feasibility of this reaction on the extended diatomic rows of $\mathrm{Au}$ on $\mathrm{Au}$ (100) seems less certain. This surface does enable the adsorption and dissociation of $\mathrm{O}_{2}$ in a way that the activation energy of dissociation is similar as that for desorption of $\mathrm{O}_{2}$. Hence, on the basis of energy one may expect that dissociation can compete with desorption. The uncertainty, however, is in the entropy change for both reactions. Desorption often has preexponential factors exceeding those of dissociation, thus favoring the former [53]. Nevertheless, we feel that our result of $\mathrm{O}_{2}$ dissociation on diatomic $\mathrm{Au}$ rows on $\mathrm{Au}(100)$ being energetically feasible is significant, as this is the only extended gold surface we have found sofar which comes close to enabling the dissociation of $\mathrm{O}_{2}$.

Another mechanism for the $\mathrm{CO}$ oxidation involves the direct reaction between molecular $\mathrm{O}_{2}$ and $\mathrm{CO}$ to $\mathrm{CO}_{2}$ and an adsorbed $\mathrm{O}$-atom. The stepped $\mathrm{Au}(310)$ surface provides a pathway for this reaction with a barrier about equal to the $\mathrm{O}_{2}$ adsorption energy. Nevertheless, we cannot be sure that this mechanism operates, as the $\mathrm{O}_{2}$ is bound to the surface in a weakly chemisorbed state. Although reaction with $\mathrm{CO}$ may be energetically feasible, the molecule can diffuse freely over the surface, and hence instead of surmounting the activation barrier to form the OCOO complex, the molecule has the alternative of moving away at no energy cost.

The results in this paper highlight the importance of sites consisting of low coordinated atoms in a particular geometry, in this case a square of four Au atoms. This ensemble appears capable of binding both molecular and dissociated oxygen with sufficient strength, that dissociation of $\mathrm{O}_{2}$ is energetically favorable. As these sites also bind $\mathrm{CO}$ sufficiently strong, reaction with atomic oxygen to form $\mathrm{CO}_{2}$ proceeds readily with a small activation barrier.

Acknowledgments We thank the National Computer Facilities NCF (Grant SH-034-08) for computer time at the Huygens Super Computer. Mr. A. Hussain acknowledges financial support from the Pakistan Higher Education Commission (HEC) and Dr A.J. Muller acknowledges financial support from Sasol Technology R\&D, South Africa to enable their stay at the Eindhoven University of Technology.

Open Access This article is distributed under the terms of the Creative Commons Attribution Noncommercial License which permits any noncommercial use, distribution, and reproduction in any medium, provided the original author(s) and source are credited.

\section{References}

1. Haruta M, Kobayashi T, Sano H, Yamada N (1987) Chem Lett 16:405

2. Bond GC, Louis C, Thompson DT (2006) Catalysis by gold, Sci., Series vol 6. Imperial College Press, London

3. Grisel RJH, Nieuwenhuys BE (2001) J Catal 199:48

4. Fu Q, Saltsburg H, Flytzani-Stephanopoulos M (2003) Science 301:935

5. Boccuzzi F, Chiorino A, Manzoli M, Lu P, Akita T, Ichikawa S, Haruta M (2001) J Catal 202:256

6. Fierro-Gonzalez JC, Anderson BG, Ramesh K, Vinod CP, Niemantsverdriet JW, Gates BC (2005) Catal Lett 101:265

7. Guzman J, Anderson BG, Vinod CP, Ramesh K, Niemantsverdriet JW, Gates BC (2005) Langmuir 21:3675

8. Valden M, Lai X, Goodman DW (1998) Science 281:1647

9. Chen M, Cai Y, Yan Z, Goodman DW (2006) J Am Chem Soc 128:6341

10. Kung MC, Davis RJ, Kung HH (2007) J Phys Chem C 111:11767

11. Mihaylov M, Ivanova E, Hao Y, Hadjiivanov K, Knozinger H, Gates BC (2008) J Phys Chem C 112:18973

12. Weiher N, Beesley AM, Tsapatsaris N, Delannoy L, Louis C, van Bokhoven JA, Schroeder SLM (2007) J Am Chem Soc 129:2240-2241

13. Lopez N, Janssens TVW, Clausen BS, Xu Y, Mavrikakis M, Bligaard T, Norskov JK (2004) J Catal 223:232

14. Hvolbaek B, Janssens TVW, Clausen BS, Falsig H, Christensen CH, Norskov JK (2007) Nano Today 2:14

15. van Bokhoven JA (2009) Chimia 63:257

16. Deng XY, Min BK, Guloy A, Friend CM (2005) J Am Chem Soc 127:9267

17. Kim TS, Stiehl JD, Reeves CT, Meyer RJ, Mullins CB (2003) J Am Chem Soc 125:2018

18. Liu ZP, Hu P, Alavi A (2002) J Am Chem Soc 124:14770

19. Fajin JLC, Cordeiro MNDS, Gomes JRB (2008) J Phys Chem C 112:17291

20. Date M, Haruta M (2001) J Catal 201:221

21. Date M, Okumura M, Tsubota S, Haruta M (2004) Angew Chem Int Ed 43:2129

22. Huang JH, Akita T, Faye J, Fujitani T, Takei T, Haruta M (2009) Angew Chem Int Ed 48:7862

23. Haruta M, Yamada N, Kobayashi T, Iijima S (1989) J Catal 115:301 
24. Liu LM, McAllister B, Ye HQ, Hu P (2006) J Am Chem Soc 128:4017

25. Xu Y, Mavrikakis M (2003) J Phys Chem B 107:9298

26. Mills G, Gordon MS, Metiu H (2002) Chem Phys Lett 359:493

27. Quinet E, Piccolo L, Daly H, Meunier FC, Morfin F, Valcarcel A, Diehl F, Avenier P, Caps V, Rousset JL (2008) Catal Today 138:43

28. Xu C, Xu X, Su J, Ding Y (2007) J Catal 252:243

29. Roldan A, Gonzalez S, Ricart JM, Illas F (2009) Chemphyschem 10:348

30. Vinod CP, Niemantsverdriet JW, Nieuwenhuys BE (2005) Phys Chem Chem Phys 7:1824

31. Vinod CP, Hans JWN, Nieuwenhuys BE (2005) Appl Catal A-Gen 291:93

32. Hussain A, Curulla Ferre D, Gracia J, Nieuwenhuys BE, Niemantsverdriet JW (2009) Surf Sci 603:2734

33. Kresse G, Hafner J (1993) Phys Rev B 47:558

34. Perdew JP, Wang Y (1992) Phys Rev B 45:13244

35. Blochl PE (1994) Phys Rev B 50:17953

36. Kresse G, Joubert D (1999) Phys Rev B 59:1758

37. Structure data of elements and intermetallic phases, LandoltBörnstein, New Series, Group B, Vol. III, Springer-Verlag, Berlin, 1971

38. Monkhorst HJ, Pack JD (1976) Phys Rev B 13:5188

39. Methfessel M, Paxton AT (1989) Phys Rev B 40:3616

40. Pulay P (1980) Chem Phys Lett 73:393
41. Head JD (1997) Int J Quant Chem 65:827

42. Henkelman G, Uberuaga BP, Jonsson H (2000) J Chem Phys 113:9901

43. Silvestrelli PL, Benyahia K, Grubisic S, Ancilotto F, Toigo F (2009) J Chem Phys 130:074702

44. Huber KP, Herzberg G (1979) Molecular spectra and molecular structure IV. Constants of diatomic molecules. Van Nostrand Reinhold, New York

45. Bader RFW (1990) Atoms in molecules: a quantum theory. Oxford University Press, Oxford

46. Mavrikakis M, Stoltze P, Norskov JK (2000) Catal Lett 64:101

47. Fajin JLC, Cordeiro MNDS, Gomes JRB (2007) J Phys Chem C 111:17311

48. Gong JL, Mullins CB (2009) Acc Chem Res 42:1063

49. Kandoi S, Gokhale AA, Grabow LC, Dumesic JA, Mavrikakis M (2004) Catal Lett 93:93

50. Wang GC, Tao SX, Bu XH (2006) J Catal 244:10

51. Getman RB, Schneider WF, Smeltz AD, Delgass WN, Ribeiro FH (2009) Phys Rev Lett 102:076101

52. Wang CM, Fan KN, Liu ZP (2007) J Am Chem Soc 129:2642

53. Roldan A, Ricart JM, Illas F (2009) Theor Chem Acc 123:119

54. Wallace WT, Leavitt AJ, Whetten RL (2003) Chem Phys Lett 368:774

55. Ding XL, Li ZY, Yang JL, Hou JG, Zhu QS (2004) J Chem Phys 120:9594 